\title{
Thyroid dysfunction from inhibitor of fibroblast growth factor receptor
}

Jeffrey Ahn' ${ }^{1}$ Justin Moyers², John Wong ${ }^{2}$ and Chung-Tsen Hsueh ${ }^{2 *}$

\begin{abstract}
Background: Thyroid dysfunction has not been previously reported in clinical trials of selective fibroblast growth factor receptor (FGFR) inhibitors including AZD4547. Herein, we report a case of worsening hypothyroidism in a patient with advanced urothelial cancer treated with AZD4547.

Case presentation: An 80-year-old Caucasian female with metastatic urothelial carcinoma failed first-line chemotherapy with gemcitabine and carboplatin and second-line treatment with atezolizumab, an inhibitor of programmed cell death ligand 1. She developed hypothyroidism at completion of atezolizumab treatment and responded to levothyroxine. Subsequently she was enrolled to a phase II study and received AZD4547 due to an actionable mutation at FGFR3 found in tumor biopsy. Two months later, she experienced recurrent hypothyroidism symptoms, and was hospitalized twice for small bowel obstruction. Her thyroid stimulating hormone level was significantly increased to $2957 \mathrm{ulU} / \mathrm{mL}$ (reference range 0.8-7.7 ulU/mL). Her levothyroxine dose was increased accordingly. Her thyroid function returned to normal 1 month afterwards, and small bowel obstruction did not recur.

Conclusion: Further reports and studies will be needed to confirm the relationship between AZD4547 and hypothyroidism. Based on this observation and possible mechanisms for thyroid dysfunction discussed in this paper, routine thyroid function monitoring in patients receiving FGFR inhibitor should be considered.
\end{abstract}

Keywords: Hypothyroidism, AZD4547, Thyroid dysfunction, Fibroblast growth factor receptor, Tyrosine kinase inhibitor, Urothelial cancer, Case report

\section{Background}

Thyroid dysfunction, especially hypothyroidism, is frequently seen in cancer patients receiving tyrosine kinase inhibitor (TKI) or immune checkpoint inhibitor treatment $[1,2]$. The incidence varies due to different mechanisms of action. Unrecognized hypothyroidism may lead to severe gastrointestinal manifestations such as decreased colonic motility, constipation and bowel obstruction [3, 4].

Fibroblast growth factor receptor (FGFR) is a transmembrane receptor tyrosine kinase family, which consists of four members (FGFR 1-4) that are involved in cell signaling by binding to fibroblast growth factors (FGFs)

\footnotetext{
*Correspondence: chsueh@lluedu

${ }^{2}$ Division of Medical Oncology and Hematology, Department of Internal Medicine, Loma Linda University, 11175 Campus Street, CSP 11015, Loma Linda, CA 92354, USA

Full list of author information is available at the end of the article
}

[5]. The downstream singling of FGFR involves mitogenactivated protein kinase (MAPK) and PI3K-AKT pathways, which are essential in cell growth and oncogenic events. Aberrations in the FGFR signaling pathway have been implicated in the development and progression of multiple solid tumor malignancies [6]. A number of novel drugs targeting the FGFR cascade have been developed and are undergoing clinical trials. AZD4547 is an orally available, small-molecule tyrosine kinase inhibitor that selectively inhibits FGFR 1-3 [7]. The drug has demonstrated anti-tumor activity in FGFR amplified gastric and non-small cell lung cancer xenograft models in mice $[8,9]$. In a phase I study of patients with advanced solid malignancies, AZD4547 was found to be well tolerated without dose-limiting toxicities, and approximately $70 \%$ of patients had stable disease $>4$ weeks [10].

Phase I and II clinical trials of AZD4547 revealed acceptable safety profiles with common adverse effects 
being gastrointestinal toxicities (nausea/vomiting, decreased appetite and bowel habit changes), fatigue, hyperphosphatemia, dry eye, epithelial and mucosal dryness, stomatitis, retinal pigment epithelial detachment, etc. [10-12]. Thyroid dysfunction has not been previously reported in trials involving FGFR inhibitors including AZD4547. Herein, we report a case of worsening hypothyroidism in a patient with advanced urothelial cancer receiving AZD4547.

\section{Case presentation}

An 80-year-old Caucasian female was referred for left renal mass and multiple expansile bone lesions resulting in back and chest wall pain in September 2016. She had a history of in situ high-grade papillary transitional cell carcinoma of the urinary bladder, status post radical cystectomy and pelvic lymph node dissection in May 2012. She underwent left renal mass biopsy which revealed invasive urothelial carcinoma. She received firstline palliative chemotherapy with gemcitabine and carboplatin along with palliative radiation therapy for pain control. Subsequently she also received denosumab, a bone modifying agent, for symptomatic bone metastases after dental evaluation. Due to progressive disease, she started second-line systemic treatment from December 2016 with atezolizumab $1200 \mathrm{mg}$ intravenously over 60 min every 3 weeks, an inhibitor of programmed cell death ligand 1 [13]. She tolerated atezolizumab well but developed progressive disease in May 2017. At the end of atezolizumab treatment course, she developed clinically significant hypothyroidism with cold intolerance, insomnia, constipation and extreme fatigue in the setting of elevated thyroid stimulating hormone (TSH) level to $21 \mathrm{uIU} / \mathrm{mL}$ (reference range $0.8-7.7 \mathrm{uIU} / \mathrm{mL}$ ). Therefore, she was started on levothyroxine, and her symptoms resolved with normalization of TSH.

Afterwards she was enrolled to a phase II study (ClinicalTrials.gov Identifier: NCT02465060) and underwent tumor biopsy at sternum for next-generation sequencing assay which revealed an actionable mutation at FGFR3. She received AZD4547 $80 \mathrm{mg}$ orally twice a day from June 2017 on clinical trial. After 2 months of AZD4547 treatment, she experienced recurrent hypothyroidism symptoms, and was hospitalized twice for small bowel obstruction responding to medical treatment. Her TSH level at that time was significantly increased to $2957 \mathrm{uIU} /$ $\mathrm{mL}$, and daily levothyroxine dose was increased from 50 to $100 \mathrm{mcg}$ accordingly. Her thyroid function returned to normal 1 month afterwards, and she did not experience recurrence of small bowel obstruction.

She achieved stable disease on AZD4547 for approximately 6 months prior to development of progressive disease. She progressed through subsequent lines of treatment with cisplatin and docetaxel and finally pemetrexed before succumbing to disease in June 2018.

\section{Discussion and conclusion}

Hyperphosphatemia has been shown to be a class-specific mechanism-based toxicity of selective FGFR inhibitors including AZD4547 with incidence ranging from 30 to $65 \%$ in clinical trials [7]. The mechanism of action is likely due to interruption of FGF23 binding to FGFR on the proximal renal tubule which results in increased phosphate reabsorption and reduced renal production of vitamin $D[10,14]$. The nonselective FGFR TKIs such as E3810 are multitarget TKIs that include FGFR and vascular endothelial growth factor receptors in their panel of targets [15]. Nonselective FGFR TKIs lack kinase selectivity and hypothyroidism has been shown to be a common adverse effect in this class of compounds.

Immune checkpoint inhibitors such as monoclonal antibodies against programmed death 1 and programmed cell death ligand 1 have been approved for the treatment of patients with locally advanced or metastatic urothelial carcinoma [16]. Most thyroid dysfunction induced by immune checkpoint inhibitors is hypothyroidism derived from immune-related thyroiditis [2]. It is recommended to monitor thyroid function prior to and during treatment with immune checkpoint inhibitors, and initiate hormone replacement therapy or medical management of hyperthyroidism as clinically indicated. In clinical studies of atezolizumab, hypothyroidism occurred in $4.6 \%$ of patients and hyperthyroidism occurred in $1.6 \%$ of patients [17]. Our patient developed symptomatic hypothyroidism after 5 months of atezolizumab treatment and responded to levothyroxine. Per study protocol, she did not receive thyroid function monitoring during subsequent treatment with AZD4547. Therefore, she developed worsened hypothyroidism leading to hospitalization with bowel obstruction.

One plausible mechanism for FGFR inhibitor inducing hypothyroidism is inhibiting the angiogenesis of thyroid gland vascular bed and subsequently causing hypoperfusion and local destruction of the organ. Presta et al. demonstrated that FGFR1 and FGFR2 are present on endothelial cells and postulated that FGFs exert their angiogenic mechanism via paracrine signaling by stromal cells [18]. Preclinical model of microvascular endothelial cells grown on a three-dimensional collagen gel, FGF2 were shown to induce cells via direct effect to invade the underlying matrix by forming capillary-like tubules and initiate angiogenesis [19]. In murine model, FGF1 and FGF1/FGF2 double knockout mice had poor wound healing compared to normal control mice [20]. In 2004, Davis et al. demonstrated that thyroxine has proangiogenic 
role in the chick chorioallantoic membrane model and its angiogenic effect is mediated by FGF2 and MAPK dependent [21].

Similar to other TKIs such as imatinib and sunitinib, cross reactivity between TKI and non-target substrates can cause side effects. A prospective study by de Groot et al. demonstrated that nine of fifteen patients with advanced medullary thyroid cancer status post thyroidectomy on levothyroxine who received imatinib had to increase thyroxine hormone requirement while on therapy. The authors hypothesized that imatinib increased thyroid hormone clearance through induction of hepatic microsomal enzymes including mixed function oxygenase and uridine diphosphate-glucuronosyltransferase [22]. Rather than affecting the thyroid gland itself, this mechanism suggests that TKI could interfere with active serum level of thyroid hormone leading to worsening of hypothyroidism similarly to what our patient experienced.

Furthermore, another possible mechanism for TKIinduced hypothyroidism is direct interference of the thyroid gland's function by blocking iodine uptake and inducing antiperoxidase activity. In a prospective phase I-II study, Mannavola et al. reviewed thyroid function test, thyroid ultrasound as well as radioiodine uptake testing of 24 patients with gastrointestinal stromal tumor treated with sunitinib. Impaired radioiodine uptake was observed by a blunted early radioactive iodine uptake curve suggesting an alteration in the uptake process [23]. Wong et al. demonstrated the antiperoxidase activity of sunitinib by looking at the effect on guaiacol oxidation and protein iodination through lactoperoxidase and concluded that the drug had one-fourth potency of propylthiouracil suggesting potential antiperoxidase activity of TKI [24].

Further reports and studies will be needed to confirm the relationship between AZD4547 and hypothyroidism. Based on this observation and possible mechanisms for thyroid dysfunction discussed in this case, routine thyroid function assessments in patients receiving FGFR inhibitor should be considered.

\footnotetext{
Abbreviations

TKI: tyrosine kinase inhibitor; FGFR: fibroblast growth factor receptor; TSH: thyroid stimulating hormone; FGF: fibroblast growth factor; MAPK: mitogenactivated protein kinase.
}

\section{Authors' contributions}

JA, JM, CTH designed the report. JW and CTH performed clinical examination and collected data. JA, JM and CTH analyzed the data and wrote the paper. All authors read and approved the final manuscript.

\section{Author details}

${ }^{1}$ Department of Internal Medicine, Loma Linda University, Loma Linda, CA 92354, USA. ${ }^{2}$ Division of Medical Oncology and Hematology, Department of Internal Medicine, Loma Linda University, 11175 Campus Street, CSP 11015 , Loma Linda, CA 92354, USA.

\section{Acknowledgements}

Not applicable.

Competing interests

The authors declare that they have no competing interests.

\section{Availability of data materials}

Data sharing not applicable to this article as no data sets were generated or analyzed.

\section{Consent for publication}

The patient involved in this study gave her informed consent authorizing use and disclosure of her protected health information.

\section{Ethics approval and consent to participate}

Not applicable. Institutional review board's statement is not needed for this case report per institutional review board's policy at Loma Linda University.

\section{Funding}

None

\section{Publisher's Note}

Springer Nature remains neutral with regard to jurisdictional claims in published maps and institutional affiliations.

Received: 21 December 2018 Accepted: 8 February 2019

Published online: 18 February 2019

\section{References}

1. Torino F, Corsello SM, Longo R, Barnabei A, Gasparini G. Hypothyroidism related to tyrosine kinase inhibitors: an emerging toxic effect of targeted therapy. Nat Rev Clin Oncol. 2009;6(4):219-28.

2. Lee H, Hodi FS, Giobbie-Hurder A, Ott PA, Buchbinder El, Haq R, Tolaney S, Barroso-Sousa R, Zhang K, Donahue H, et al. characterization of thyroid disorders in patients receiving immune checkpoint inhibition therapy. Cancer Immunol Res. 2017;5(12):1133-40.

3. Shafer RB, Prentiss RA, Bond JH. Gastrointestinal transit in thyroid disease. Gastroenterology. 1984;86(5 Pt 1):852-5.

4. Cole P, Petrie JC, Bewsher PD. Intestinal obstruction and hypothyroidism. BMJ. 1969;3(5671):655-6.

5. Turner N, Grose R. Fibroblast growth factor signalling: from development to cancer. Nat Rev Cancer. 2010;10(2):116-29.

6. Babina IS, Turner NC. Advances and challenges in targeting FGFR signalling in cancer. Nat Rev Cancer. 2017;17(5):318-32.

7. Chae YK, Ranganath K, Hammerman PS, Vaklavas C, Mohindra N, Kalyan A, Matsangou M, Costa R, Carneiro B, Villaflor VM, et al. Inhibition of the fibroblast growth factor receptor (FGFR) pathway: the current landscape and barriers to clinical application. Oncotarget. 2017;8(9):16052-74.

8. Xie L, Su X, Zhang L, Yin X, Tang L, Zhang X, Xu Y, Gao Z, Liu K, Zhou M, et al. FGFR2 gene amplification in gastric cancer predicts sensitivity to the selective FGFR inhibitor AZD4547. Clin Cancer Res. 2013;19(9):2572-83.

9. Zhang J, Zhang L, Su X, Li M, Xie L, Malchers F, Fan S, Yin X, Xu Y, Liu K, et al. Translating the therapeutic potential of AZD4547 in FGFR1-amplified non-small cell lung cancer through the use of patient-derived tumor xenograft models. Clin Cancer Res. 2012;18(24):6658-67.

10. Saka H, Kitagawa C, Kogure Y, Takahashi Y, Fujikawa K, Sagawa T, Iwasa S, Takahashi N, Fukao T, Tchinou C, et al. Safety, tolerability and pharmacokinetics of the fibroblast growth factor receptor inhibitor AZD4547 in Japanese patients with advanced solid tumours: a phase I study. Invest New Drugs. 2017;35(4):451-62.

11. Van Cutsem E, Bang YJ, Mansoor W, Petty RD, Chao Y, Cunningham D, Ferry DR, Smith NR, Frewer P, Ratnayake J, et al. A randomized, open-label study of the efficacy and safety of AZD4547 monotherapy versus paclitaxel for the treatment of advanced gastric adenocarcinoma with FGFR2 polysomy or gene amplification. Ann Oncol. 2017;28(6):1316-24. 
12. Paik PK, Shen R, Berger MF, Ferry D, Soria JC, Mathewson A, Rooney C, Smith NR, Cullberg M, Kilgour E, et al. A phase Ib open-label multicenter study of AZD4547 in patients with advanced squamous cell lung cancers. Clin Cancer Res. 2017;23(18):5366-73.

13. Liu B, Song Y, Liu D. Recent development in clinical applications of PD-1 and PD-L1 antibodies for cancer immunotherapy. J Hematol Oncol. 2017;10(1):174.

14. Gattineni J, Alphonse P, Zhang Q, Mathews N, Bates CM, Baum M. Regulation of renal phosphate transport by FGF23 is mediated by FGFR1 and FGFR4. Am J Physiol Renal Physiol. 2014;306(3):F351-8.

15. Dieci MV, Arnedos M, Andre F, Soria JC. Fibroblast growth factor receptor inhibitors as a cancer treatment: from a biologic rationale to medical perspectives. Cancer Discov. 2013;3(3):264-79.

16. Mehta K, Patel K, Parikh RA. Immunotherapy in genitourinary malignancies. J Hematol Oncol. 2017;10(1):95.

17. Barroso-Sousa R, Barry WT, Garrido-Castro AC, Hodi FS, Min L, Krop IE, Tolaney SM. Incidence of endocrine dysfunction following the use of different immune checkpoint inhibitor regimens: a systematic review and meta-analysis. JAMA Oncol. 2018;4(2):173-82.

18. Presta M, Dell'Era P, Mitola S, Moroni E, Ronca R, Rusnati M. Fibroblast growth factor/fibroblast growth factor receptor system in angiogenesis. Cytokine Growth Factor Rev. 2005;16(2):159-78.
19. Pepper MS, Ferrara N, Orci L, Montesano R. Potent synergism between vascular endothelial growth factor and basic fibroblast growth factor in the induction of angiogenesis in vitro. Biochem Biophys Res Commun. 1992;189(2):824-31.

20. Lieu C, Heymach J, Overman M, Tran H, Kopetz S. Beyond VEGF: inhibition of the fibroblast growth factor pathway and antiangiogenesis. Clin Cancer Res. 2011;17(19):6130-9.

21. Davis FB, Mousa SA, O'Connor L, Mohamed S, Lin HY, Cao HJ, Davis PJ. Proangiogenic action of thyroid hormone is fibroblast growth factor-dependent and is initiated at the cell surface. Circ Res. 2004;94(11):1500-6.

22. de Groot JW, Zonnenberg BA, Plukker JT, van Der Graaf WT, Links TP. Imatinib induces hypothyroidism in patients receiving levothyroxine. Clin Pharmacol Ther. 2005;78(4):433-8.

23. Mannavola D, Coco P, Vannucchi G, Bertuelli R, Carletto M, Casali PG, Beck-Peccoz P, Fugazzola L. A novel tyrosine-kinase selective inhibitor, sunitinib, induces transient hypothyroidism by blocking iodine uptake. J Clin Endocrinol Metabol. 2007:92(9):3531-4.

24. Wong E, Rosen LS, Mulay M, Vanvugt A, Dinolfo M, Tomoda C, Sugawara $M$, Hershman JM. Sunitinib induces hypothyroidism in advanced cancer patients and may inhibit thyroid peroxidase activity. Thyroid. 2007;17(4):351-5.
Ready to submit your research? Choose BMC and benefit from:

- fast, convenient online submission

- thorough peer review by experienced researchers in your field

- rapid publication on acceptance

- support for research data, including large and complex data types

- gold Open Access which fosters wider collaboration and increased citations

- maximum visibility for your research: over 100M website views per year

At BMC, research is always in progress.

Learn more biomedcentral.com/submissions 